\title{
Fenomenología
}

\section{Percepción del equipo de enfermería sobre el enfoque lúdico al niño hospitalizado}

Nursing staff perception of nursing on approach to child hospitalized ludica

\section{Percepção da equipe de enfermagem sobre a abordagem lúdica à criança hospitalizada}

\begin{abstract}
Ana Cláudia Seus Falke ${ }^{1}$, Viviane Marten Milbrath², Vera Lucia Freitag ${ }^{3}$
${ }^{1}$ Enfermeira. Pelotas - Rio Grande do Sul (Brasil).E-mail: anaclaudiafalke@gmail.com.

${ }^{2}$ Doutora em Enfermagem. Professora Adjunta da Universidade Federal de Pelotas (UFPel). Enfermeira. Pelotas - RS (Brasil). Email: vivianemarten@hotmail.com

${ }^{3}$ Doutoranda em Enfermagem da Universidade Federal do Rio Grande do Sul (UFRGS). Mestre em Ciências. Especialista em Gestão de Organização Pública em Saúde. Bolsista pela Coordenação e Aperfeiçoamento de Pessoal de Nível Superior (CAPES). Enfermeira.

Cómo citar este artículo en edición digital: Falke, A.C.S., Milbrath, V.M., \& Freitag, V.L. (2018). Percepción del equipo de enfermería sobre el enfoque lúdico al niño hospitalizado. Cultura de los Cuidados (Edición digital), 22(50). Recuperado de http://dx.doi.org/10.14198/cuid.2018.50.02
\end{abstract}

Correspondencia: Rua São Manoel, 963. Bairro Rio Branco. Porto Alegre - RS. Fone para contato (55) 996598793

Correo electrónico: verafreitag@hotmail.com

Recibido: 28/06/2017; Aceptado: 15/10/2017

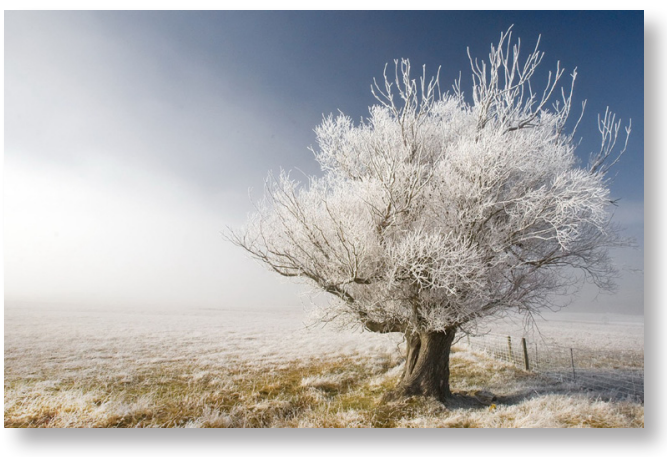

ABSTRACT

Objective: To know the perception of the nursing team about the playful approach to hospitalized children.

Methodology: exploratory-descriptive qualitative study in Pediatrics in a hospital in southern Rio Grande do Sul School with eight nursing team professionals. To collect data, we used the semi-structured interview. The in- formation was interpreted through thematic analysis of Minayo.

Results: it was observed that the nursing staff does not have the technical and scientific preparation to use a playful approach in providing nursing care, as well as some ignorant of the concept and the techniques applied to the play therapy, this issue has had little or no approach in academic or vocational training of respondents.

Conclusion: it is necessary that this mode is entered in undergraduate courses and that the institutions promote playful care that professionals can use this instrument care, thereby improving the care provided to hospitalized children.

Keywords: Child Hospitalized, Playful Approach, Nursing Professionals, Care. 


\section{RESUMEN}

Objetivo: Conocer la percepción del equipo de enfermería sobre el enfoque lúdico para los niños hospitalizados.

Metodología: estudio cualitativo exploratorio-descriptivo en pediatría en un hospital en el sur de Rio Grande do Sul escuela con ocho profesionales del equipo de enfermería. Para recopilar los datos, se utilizó la entrevista semiestructurada. La información fue interpretada a través de análisis temático de Minayo.

Resultados: Se observó que el personal de enfermería no tiene la preparación técnica y científica para utilizar un enfoque lúdico en la prestación de cuidados de enfermería, así como algunos ignorantes del concepto y las técnicas aplicadas a la terapia de juego, este problema ha tenido poca o ninguna enfoque en la formación académica o profesional de los encuestados.

Conclusión: es necesario que este modo se introduce en los cursos de grado y que las instituciones de promover el cuidado lúdico que los profesionales pueden utilizar este instrumento de cuidado, con objeto de optimizar la atención a los niños hospitalizados.

Palabras clave: Niño Hospitalizado, Enfoque Lúdico, Los profesionales de Enfermeira, Cuidado.

\section{RESUMO}

Objetivo: conhecer a percepção da equipe de enfermagem sobre a abordagem lúdica à criança hospitalizada.

Metodologia: estudo qualitativo exploratório-descritivo, realizado na pediatria de um Hospital Escola do sul do Rio Grande do Sul, com oito profissionais da equipe de enfermagem. Para a coleta de dados, utilizou-se a entrevista semi-estruturada. As informações foram interpretadas por meio da análise temática de Minayo.

Resultados: observou-se que a equipe de enfermagem não possui o preparo técnico-científico para utilizar a abordagem lúdica na prestação de assistência de enfermagem, visto que além de alguns desconhecerem o conceito e as técnicas aplicadas à ludoterapia, esse tema teve escasso ou nenhuma abordagem na formação acadêmica ou profissional dos entrevistados.

Conclusão: faz-se necessário que tal modalidade seja inserida nos cursos de graduação e ainda que a instituições promovam o cuidado lúdico para que os profissionais possam utilizar deste instrumento do cuidado, melhorando assim a assistência prestada à criança hospitalizada.

Palavras chave: Criança hospitalizada, Abordagem lúdica, Profissionais de Enfermagem, Cuidado.

\section{INTRODUÇÃO}

O cuidado de enfermagem à criança hospitalizada tem sido no intuito de amenizar os traumas devido ao processo de internação, reduzindo assim o sofrimento, promovendo-lhe saúde e fazendo com que essa situação seja a menos traumática possível. Para tanto, os profissionais da saúde necessitam compreender o universo infantil e buscar formas adequadas de interação com a criança.

Nesse aspecto a brincadeira é considerada uma aliada ao processo de hospitalização infantil visando amenizar o desconforto de o ambiente hospitalar, e também dos diversos procedimentos realizados na criança. Sendo que a hospitalização representa para a criança uma situação complexa e traumatizante, visto 
que sua rotina é modificada. Encontra-se em um ambiente impessoal, cheios de tabus e significados, distantes dos seus amigos e familiares e repletos de pessoas estranhas e que geralmente a todo o momento a tocam e realizam procedimentos que causam desconforto e dor (Coà, Pettengil, 2011).

Destarte, a abordagem lúdica proporciona uma permanência ou estadia de tranquilidade para as crianças além de laços de amizades (Maia, Ribeiro, Borba, 2011). Ajuda na comunicação e promove a construção e reconstrução da própria individualidade pela criança (Lemos et al. 2010).

Contudo, frisa-se a relevância do preparo do profissional de enfermagem na abordagem à criança, analisando sua concepção e informando quanto às sensibilidades e intensidades dos estímulos dolorosos, amenizando o estresse provocado pelos procedimentos, especialmente os invasivos.

Para que os traumas resultantes da hospitalização infantil sejam diminuídos e o cuidado humanizado seja concedido, é necessário que os profissionais de saúde reúnam seus recursos tecnológicos e a percepção das fases de crescimento e desenvolvimento infantil, agregando às circunstâncias tais como: o comparecimento e apoio de familiares, disponibilidade afetiva dos profissionais da equipe de enfermagem e informações, atividades recreativas, lúdicas e etc. (Magnabosco, Tonelli \& Souza, 2008).

Dentre as formas de abordagem lúdica salienta-se o brincar terapêutico organizado pelo profissional que cuida da criança, destinada a promover seu bem-estar e saúde. $\mathrm{O}$ brincar surge para modificar o cotidiano dessa hospitalização, deve se valorizar gestos, apatia, choro, medos demonstrados pela criança, pois podem ser indicativos de necessidade acolhimento e segurança (Lemos et al. 2010).
Os autores Leite \& Shimo (2007) destacam o uso do brinquedo como um valioso instrumento no preparo de crianças para procedimentos, que segundo ele não só possibilita a melhor compreensão da situação bem como para extravasar os sentimentos da criança, mas também subsidia a equipe de saúde para o entendimento das suas necessidades, formando assim laços de confiança que perdurem por todo período de hospitalização. Nessa conjuntura, os enfermeiros e técnicos de enfermagem podem utilizar o brincar como estratégia de cuidado à criança hospitalizada, durante as rotinas diárias, preparo para cirurgia, procedimentos invasivos, dolorosos e desagradáveis (Frota et al. 2007).

Para a preparação da criança deve-se levar em conta, a idade e o tipo de procedimento. Para tal, destacam-se algumas diretrizes gerais no seu preparo, tais como: avaliar o nível de compreensão dos pais e da criança; planejar a abordagem com base na idade de desenvolvimento da criança e no nível de conhecimento existente; inserir os pais no cuidado, assim como informá-los de suas funções e eficácia, enfatizar os processos sensoriais do procedimento (sentir, cheirar, ver, tocar), demostrar o que ela pode fazer durante o procedimento (segurar boneca, apertar mão, etc.), explicar os benefícios positivos do procedimento e explicar ao final do procedimento os efeitos agradáveis posteriores (alívio da dor, ver os pais, etc.) (Jansen, Santos \& Favero, 2010).

Acredita-se que a realização deste estudo seja relevante, pois busca fomentar discussões e reflexões nos profissionais da equipe de saúde a respeito da utilização do lúdico como instrumento de abordagem e humanização do cuidado a criança, para que possam cuidar e promover as condições de desenvolvimento adequadas para este, e as crianças tenham um 
cuidado humanizado adequado para sua idade, de maneira que a hospitalização se torne menos traumatizante para ela e sua família. Neste sentido, o objetivo desse estudo foi conhecer a percepção da equipe de enfermagem em relação ao lúdico na abordagem a criança hospitalizada.

\section{METODOLOGIA}

Trata-se de um estudo descritivo e exploratório a luz de uma abordagem qualitativa, realizado no período de junho a dezembro do ano de 2015, na pediatria de um Hospital Escola do sul do Rio Grande do Sul. Os Participantes do estudo foram oito profissionais da equipe de enfermagem, sendo três enfermeiros e cinco técnicos de enfermagem. Os quais foram identificados por codinomes E1, E2, respectivamente para enfermeiro e TE1, TE2, respectivamente para técnico em enfermagem. A delimitação do número de participantes observou o critério de saturação dos dados, ou seja, o prosseguimento das entrevistas ocorreu enquanto surgiam dados novos, e as mesmas foram suspensas no momento em que os dados se tornaram repetitivas (Minayo, 2012).

Foram utilizados como critérios de inclusão: ser profissional enfermeiro ou técnico/ auxiliar de enfermagem que trabalha no local do estudo há pelo menos um ano e permitir a gravação da entrevista. E, como critérios de exclusão estar de férias ou licença saúde no período da coleta das informações. Os participantes assinaram o Termo de Consentimento Livre e Esclarecido.

As informações foram coletadas por meio de entrevistas semiestruturadas, dentre as quais os pesquisadores, primeiramente realizaram as questões que traçaram o perfil dos entrevistados, após efetuaram os seguintes questionamentos: Qual a sua opinião sobre a abordagem lúdica? Você já usou a abordagem lúdica na sua prática profissional? Em sua opinião existe alguma vantagem ou desvantagem na abordagem lúdica?

As entrevistas foram realizadas em uma sala reservada, no próprio hospital, gravadas e transcritas logo após a sua realização. Para interpretação das informações adotou-se a análise temática (Minayo, 2012).

Em atenção às normas da pesquisa, envolvendo os seres humanos, o projeto foi submetido ao Comitê de Ética em Pesquisa da Faculdade de Medicina da Universidade Federal de Pelotas para avaliação, sendo aprovado sob o número 1.195.440.

\section{RESULTADOS E DISCUSSÃO}

Com a análise dos dados emergiram duas categorias: Conhecendo a percepção da equipe de enfermagem sobre a abordagem lúdica à criança hospitalizada e $\mathrm{O}$ que leva os profissionais a não colocarem em prática a abordagem.

Conhecendo a percepção da equipe de enfermam sobre a abordagem lúdica à criança hospitalizada

Ao dialogar com os participantes sobre seu entendimento em relação à abordagem lúdica encontrou-se que alguns participantes a associam com a utilização de recursos matérias que permitam um ambiente acolhedor e mais próximo do vivido pela criança:

É proporcionar um ambiente mais próximo do ambiente dela [...] menos sistemático [...] mais confortável (E2).

Entendo que seja recursos com brinquedos e histórias para a criança entender o que está acontecendo (T/A2.)

Recursos com brinquedos e materiais que a gente não tem aqui. (T/A3). 
Usar o brinquedo para abordar (E1).

Utiliza-se jogos e brinquedos para a criança manusear (E3).

Os depoimentos demonstraram que os participantes entendem que o lúdico visa proporcionar a criança um ambiente hospitalar acolhedor que se apresente próximo ao ambiente em que ela vive, bem como a utilização de brinquedos, brincadeiras, conto de histórias a fim de familiarizar a criança a esse novo e desconhecido local. No entanto a participante $\mathrm{T} / \mathrm{A} 3$ refere que a instituição não dispõe de recursos materiais para uma abordagem lúdica por meio do brinquedo. No entanto salienta-se que o lúdico pode acontecer sem brinquedos, pode ser em forma de brincadeiras, no entanto esse processo cabe à enfermagem explorar esses recursos e coloca-los em prática.

A equipe de enfermagem deve prever; prover e facilitar sua participação nos diferentes tipos de brincadeiras, além de participar desta atividade interagindo educativamente, contemplando toda a realidade e integralidade desta criança. Ao ser acolhida a criança sente-se segura, fica mais colaborativa e tem uma estadia mais tranquila permitindo-a extravasar seus sentimentos (Lima, Santos, 2015).

Estudo desenvolvido na Àsia, com 106 crianças 6-14 anos de idade, cujo objetivo foi determinar se uma terapêutica por meio do jogo leva a uma redução significativa da ansiedade perioperatória, manifestações emocionais negativas e dor no pós-operatório de crianças submetidas à cirurgia eletiva de internação e na ansiedade perioperatória dos pais. Os resultados mostraram que uma abordagem por meio da ludoterapia é útil e potencialmente eficaz para preparar as crianças para a cirurgia, reduzindo a ansiedade das crianças e dos

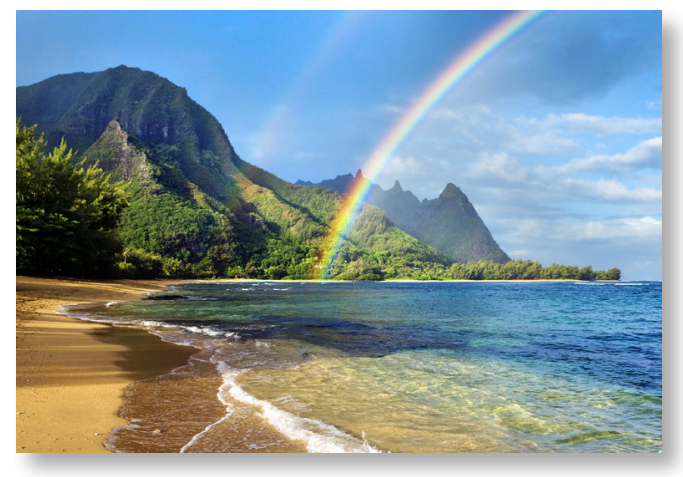

seus pais durante o período perioperatório. A redução da ansiedade pode levar à redução da dor pós-operatória, o que acabará por melhorar o bem-estar físico e psicológico das crianças (He et al. 2014).

Dessa maneira, a abordagem lúdica caracteriza-se por uma atividade de entretenimento, que dá prazer e diverte as pessoas envolvidas e está relacionado com jogo e o ato de brincar e que ajuda no desenvolvimento intelectual, emocional e auxilia a criança a se perceber no mundo (Brito et al. 2009).

Outros participantes referiram compreender a abordagem lúdica como um cuidado diferenciado:

É um tratamento diferenciado [...] cuida-se como um todo e brinca-se (T/A1).

É abordar de forma descontraída estabelecendo vinculo e confiança (T/A1).

Os depoimentos salientam a abordagem lúdica como uma forma de cuidar como um todo, integralmente, valorizando toda a complexidade que concerne o ser criança e principalmente o ser criança vivenciando a vulnerabilidade de estar hospitalizada. Para isso, destacam a importância da criação do vínculo e da confiança, que encontram no brincar um aliado para essa aproximação.

Cada criança é única e possui características próprias, e precisa ser vista integralmente 
na sua singularidade, pois assim, é possível contribuir para seu desenvolvimento e crescimento. Quando a proposta de assistência é integral, portanto humanizada, esta experiência estressante que é causada pelo processo de adoecimento e hospitalização pode ser amenizada com fornecimento de certas condições, como presença de familiares, contato com outras crianças, disponibilidade afetiva dos trabalhadores de saúde, informação, atividades recreativas, entre outras (Paladino, Carvalho \& Almeida, 2014).

Neste sentido o olhar humanizado na saúde acontece no encontro entre duas pessoas, ampliando o olhar para os sujeitos envolvidos no processo do cuidar, especialmente em relação àquele que necessita de cuidados, pois não se limita ao corpo biológico (Almeida, 2012), deve ir além buscando alternativas de cuidado relacionado à fase de desenvolvimento do ser cuidado, neste sentido, a criança hospitalizada.

Em contrapartida, dois dos participantes, referiram dúvidas sobre o que seria a abordagem lúdica:

Não sei muito bem, mas acho que é brincar (A4).

Eu não sei muito bem, deve ser brincar algo $\operatorname{assim}(T / A 2)$.

Para estas participantes há dúvidas do que seja uma abordagem lúdica, não entendem muito bem, imaginam que pode ser o brincar. Há uma lacuna nas formações dos cursos de enfermagem em relação a essa abordagem lúdica nas disciplinas de formação, muitas vezes focado no curativo e não mostram maneiras simples e eficazes de desenvolvimento do processo de trabalho da enfermagem. Por outro lado, a instituição contratante não dispõe de formação para capacitação de profissionais que atuam em ambientes onde são atendidas as crianças.

Segundo Castro (2014) muitos profissionais desconhecem a abordagem lúdica devido à falta de capacitações nos serviços e conhecimento durante os cursos de formação. Neste contexto compreende-se a necessidade de enfatizar, a relevância da humanização, resultando assim na modificação da imagem negativa que a hospitalização representa para a criança, além de contribuir para a reflexão sobre a vulnerabilidade das crianças e a necessidade de prestar uma assistência com qualidade, visto que os traumas que se passam na infância influenciam na construção da personalidade do indivíduo.

Também foi conversado com participantes sobre como conhecerem a abordagem lúdica e eles referiram terem tido os primeiros contatos através da interação com profissionais recreacionistas e com grupos de alunos de projetos de extensão da universidade:

Conheci através de uma recreacionista que tínhamos aqui ela trabalhava com isso e trabalhava a equipe sinto falta disso até para melhorar minha prática (T/A3),

Já tinha ouvido falar na TV e com alunos de grupos que veem aqui vestidos de palhaçose brincam (T/A3).

Conheço porque ouvi falar entre os alunos tem projetos com cachorros e os doutores da alegria (T/A1).

Pode-se observar pelas falas dos participantes aprenderam o que é atividade lúdica com grupos, recreacionista e projetos desenvolvidos na unidade em que trabalha, uma delas dizem ter observado também na televisão. A interação com grupos, extensionistas e recreacionista é muito importante, pois engloba os profissionais que estão cuidando, 
há uma troca de conhecimentos significativa. Mas é importante que o profissional traga esse cuidado à sua prática, não ficando somente nos momentos em que os atores desenvolvem. Esse é um espaço rico, pois dá oportunidade para realização de atividades de extensão para realizarem brincadeiras ilustrações, contar histórias, aproximando-se trocando conhecimento e interagindo com as crianças.

É essencial que em uma unidade pediátrica possua uma sala de recreação com brinquedos e um recreacionista, que de suporte para essas crianças terem momentos de laser e interação, visto que a enfermagem tem rotinas e procedimentos para fazer, e a recreacionista pode oferecer esse apoio em momentos que as crianças mais precisam auxiliando a enfermagem no cuidado (Sikilero, Morselli \& Duarte, 1997, Almeida, 2010).

Então a relevância das atividades extensionistas abre caminhos para elucidar um ponto de fundamental importância: a articulação ensino/pesquisa/extensão. Segundo Biscarde et al. (2014), os programas de extensão universitária desvelam a importância de sua existência na relação estabelecida entre instituição e sociedade, que se consolidam pela aproximação e pela troca de conhecimentos e experiências entre professores, alunos e população, pela possibilidade de desenvolvimento de processos de ensino-aprendizagem a partir de práticas cotidianas aliadas ao ensino e pesquisa, especialmente pelo fato de propiciar o confronto da teoria com o mundo real de necessidades e desejos.

Por último, destaca-se que a promoção do brincar no espaço da hospitalização infantil requer uma discussão mais ampla que ultrapasse os limites de cada instituição, faz se necessário que tal temática seja contemplada efetivamente no campo das políticas públicas voltadas para a saúde da criança e elas devem assegurar a melhora das intervenções, técnicas e promover conhecimentos multidisciplinares que possibilite a prática tanto pelos alunos durante a graduação em programas de extensão e profissionais (Falbo et al. 2012).

Uma participante referiu que a aproximação ocorreu por meio da busca de conhecimento na literatura científica e outra pela sua experiência profissional.

Já havia lido isso em artigos na literatura até porque é bem antigo isso (E2).

$\mathrm{Na}$ verdade minha graduação é muito antiga e nunca se falou sobre isso descobri sozinha através da minha experiência profissional (E1).

Uma das profissionais buscou na literatura científica, outra na sua prática. Percebe-se a importância da universidade dar suporte para que esses futuros profissionais busquem o conhecimento e que construam seu conhecimento durante a graduação para que na sua vida profissional possam obter sucesso e deem um atendimento de qualidade aos seus pacientes. Também vale salientar que a busca do profissional em artigos científicos é plausível, pois se sabe que muitos se limitam ao que trazem da universidade, não encontrando espaço para atualização.

Isso implica em rever a formação acadêmica com o propósito de inserir conteúdos que enfatizem a atual lógica de assistência à saúde: a humanização e a integralização da assistência. Também estimulá-los a buscar o desconhecido para estar se atualizando. Com a humanização no processo de cuidar, é possível vislumbrar a possibilidade de formar profissionais que desenvolvam o cuidado aos pacientes, não só com procedimentos técnicos, mas tendo como foco as necessidades do cliente, observando a maior interação e parti- 
cipação deste no seu processo de recuperação e cura, um cuidado humano e solidário (Cruz, Rocha \& Marques, 2013). A universidade não tem o dever de ensinar o aluno tudo, mas deve abrir os horizontes e ensinar esse aluno a estar em busca do conhecimento, pois ele está sempre em construção.

Outro ponto abordado nas entrevistas foi à opinião dos participantes em relação à abordagem lúdica:

Acho-a muito importante porque eles brincam e ficam mais receptivos fica um ambiente bom (T/A1).

Ela é ótima porque favorece uma amizade com a criança e a família que às vezes é difícil (T/A2).

Acredito que funcione muito bem, pois favorece a aceitação dos procedimentos e medicação (T/A4).

Ela é um recurso muito bom porque tem criança que tem muito medo ou muito desconfiadas e abordagem ajuda a conquista-las, mas para isso as pessoas devem ser capacitadas e ter apoio da chefia para ter continuidade (T/A1).

Acho que deixa a criança mais a vontade e distrai (A3)

$\mathrm{Na}$ percepção sobre a abordagem lúdica, a maioria dos entrevistados concorda que o brincar é uma atividade importante e que facilita os procedimentos a serem realizados, pois é uma maneira de conquistar a criança, fazendo amizade e auxiliando na receptividade pela equipe, bem como fica um ambiente melhor. Sabe-se que o brincar é essencial para a vida da criança e importante para seu desenvolvimento motor, emocional, mental e social, e o meio de comunicação que ela possui para expressar seus sentimentos, suas ansiedades e suas frustrações e vê de maneira positiva a abordagem.
Segundo Nunes et al. (2013) em sua pesquisa sobre a importância da brinquedoteca hospitalar todos os participantes consideraram que brincar ajuda na recuperação da criança e consideram que a atividade é imprescindível no âmbito hospitalar.

Estudo desenvolvido na China com o objetivo de avaliar os efeitos da Entonox e a terapia de jogo, e em combinação para aliviar a dor de procedimentos em crianças de 4-15 anos. Participaram do estudo 123 crianças, divididas em quatro grupos: O Grupo A recebeu Entonox, o Grupo B recebeu terapia de jogo, o Grupo C recebeu Entonox e terapia de jogo, e o Grupo D recebeu intervenções padrão existentes. Os resultados indicaram que todas as três intervenções foram eficazes na redução dos escores de dor quando comparado com o grupo controle. Jogar é uma terapia tão potente como Entonox no alívio da dor processual, embora não houvesse nenhum efeito aditivo sobre o alívio da dor quando ludoterapia e Entonox foram combinado (Mohan et al. 2015).

Neste sentido, pode-se observar o efeito positivo da ludoterapia no cuidado à criança. A enfermagem poderá lançar mão dessa alternativa de cuidado, diminuindo a dor e outros fatores associados à hospitalização, evitando até mesmo o uso de analgésicos e deixando acriança mais a vontade neste novo ambiente.

Em contrapartida, um profissional apesar de reconhecer a importância da abordagem lúdica, acredita que sua utilização pode ser uma postergação de sofrimento para a criança, como pode-se ver na fala a seguir:

Acho que é importante claro, há situações e situações existem momentos em que tem que relacionar com o caso clínico da criança [...] porque tens que fazer o procedimento e não adianta ficar brincando porque só vai adiando 


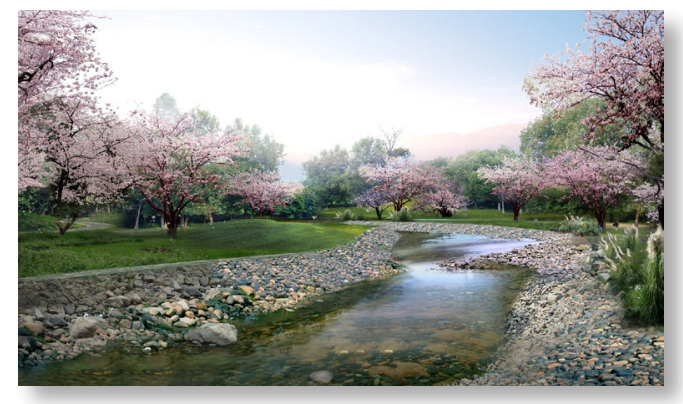

e quanto mais demora mais sofrido é para a criança (E1).

Segundo Schneider e Medeiros (2011), a abordagem lúdica é imprescindível na realização de qualquer procedimento. Estudos constatam que quando a criança é preparada para uma punção venosa, utilizando o brinquedo terapêutico, elas tornam-se cooperativas durante o procedimento além de reduzir o estresse e desgaste físico e o emocional.

Nunca é perda de tempo usar de recursos lúdicos para tornar o cuidado mais humanizado pelo contrario a criança sente- se mais segura e passa a confiar no profissional colaborando com o tratamento proposto, sentindo-se tranquila e consequentemente os cuidadores presentes.

\section{O que leva os profissionais a não colocarem em prática a abordagem.}

Ao dar voz aos participantes sobre o que os leva a utilizar ou não a abordagem lúdica, percebeu-se a preocupação com cumprir rotinas e procedimentos diários o que segundo os participantes atrapalha no uso da abordagem lúdica no seu dia-a-dia, como se pode ver nos depoimentos:

Não muito, pouco por causa da rotina diária (T/A4).

Já, já coloquei nariz de palhaço e brinquei junto, mas se perdeu um pouco e sempre tem a rotina para cumprir (T/A3).
Algumas vezes sim, não muito porque procuramos mais é fazer os procedimentos (T/A2).

Eu não consigo me avaliar, mas em alguns momentos sim, às vezes tu quer fazer, mas os colegas puxam o tapete (T/A1).

Já usei em momentos que a criança tá muito chorosa, com medo (E2).

Sim usei para tentar diminuir o medo (E1).

Em alguns momentos acho que sim (E3).

A maioria dos participantes relatou que já usou em alguns momentos a abordagem lúdica, referindo que o que atrapalha é a rotina e o excesso de atividades para serem realizadas, fazendo com que fique de lado a prática da abordagem lúdica, um dos entrevistados comenta que não utiliza por causa da rotina a ser cumprida.

Os autores Jansen, Santos \& Favero (2010) afirmam que os profissionais de saúde, podem priorizar os procedimentos técnicos, deixando de considerar os aspectos psicológicos no preparo da criança que precisa ser submetida aos procedimentos invasivos e dolorosos, como aplicação medicamentos, curativos, devido à demanda e muitas vezes uma rotina vigorosa.

Segundo Lima \& Santos (2015) a intervenção lúdica facilita a comunicação, possibilita a construção e reconstrução da própria individualidade pela criança, aspecto este bastante fragilizado pelo processo de hospitalização, constituindo-se como um recurso autocicatrizante na infância. Nesta perspectiva, o brincar deve fazer parte do cuidado à criança hospitalizada, ocupando um lugar de destaque no âmbito da promoção da saúde e atendimento integral à criança.

O cuidado técnico deve ser considerado humano, e, para isso, é necessário o encontro entre o expressivo e o técnico. Assim, não se pode separar o procedimento técnico da re- 
lação interpessoal, pois a tecnologia pode ser controlada por pessoas. Essas inferências levam à reflexão sobre a necessidade de instigar os profissionais enfermeiros a compreenderem o desenvolvimento do cuidado em suas práticas, seus significados e delimitações (Acioli, Kebian \& Faria, 2014), compreendendo que o cuidar em sentido mais amplo, entendido como processo interativo, precisa ser vivido.

Nessa perspectiva existe uma necessidade de sensibilização dos profissionais da enfermagem em relação à assistência que precisa ir além do tratamento da doença, passando também a preocupar-se com todas as outras necessidades da criança. É por meio da brincadeira que a criança explora e compreende o mundo ao seu redor, o brincar é uma forma da criança se relacionar com o mundo que a cerca, de se comunicar e expressar seus sentimentos, frustrações e ansiedades, o que de outra forma não seria tão possível devido sua imaturidade emocional (Paladino, Carvalho \& Almeida, 2014).

$\mathrm{O}$ cuidado lúdico facilita o cuidado à criança, no hospital, pois através dele a criança se ambienta na unidade e com os profissionais da saúde que lhe assistem. Ela se distrai, sente-se mais confiante, com menos medo, isto faz parte do tratamento.

Os participantes ao serem questionados sobre as vantagens e desvantagens que percebem na utilização da abordagem lúdica encontrou-se que compreendem que só existem aspectos positivos na utilização, como se pode ver nos depoimentos a seguir:

Só existem vantagens, só tem a contribuir, desvantagem não acredito que tenha (T/A1).

Vantagens são todas, desvantagem não tem é muito bom para eles (T/A3).

Só existem vantagens porque a criança passa a confiar em ti (T/A4).
Ela é muito vantajosa para a criança e família, só há benefícios (E3).

Não acho que exista desvantagem, mas a questão é praticar (T/A2).

Existem vantagens para o beneficio da criança inclusive a melhora, só que às vezes não conseguimos cumprir nem o que está na rotina. (E2).

Existem vantagens porque tu cativas a criança e a conquista e não vejo desvantagens (T/A1).

A maioria dos participantes acha a abordagem lúdica muito vantajosa por ajudar na recuperação da criança e por ajudar a diminuir os traumas da hospitalização e não veem desvantagens, mas alguns falaram na desvantagem do tempo devido à rotina atrapalhar $\mathrm{e}$ por preferirem focar diretamente num procedimento rápido.

Por meio da brincadeira, as crianças aprendem aquilo que ninguém pode ensinar. Compreendem sobre o mundo e como enfrentar esse ambiente de objetos, tempo, espaço, estrutura e pessoas. Elas aprendem sobre si próprias estando dentro deste ambiente e o que podem fazer, como se relacionar com as coisas e com as situações, inclusive a se adaptar as demandas cobradas pela sociedade (Jansen, Santos \& Favero, 2010).

Dentre as vantagens da abordagem lúdica destaca-se que ela permite à criança o desenvolvimento de inúmeras habilidades, fato que se torna importante quando se discute a hospitalização infantil. Pesquisas sobre o quanto o brincar faz bem no desenvolvimento da criança apontam, que o brincar proporciona o desenvolvimento físico, de habilidades e coordenação, além de aumentar o desenvolvimento cognitivo propiciando a imaginação, criatividade, comunicação, desenvolvimento 
social, memória, capacidade de assumir regras, desenvolvimento da autoestima e auto conceito, aprender a identificar suas emoções (Santos, 2015).

Apenas um participante elencou desvantagens:

Em certos casos é desvantajoso pelo tempo e por adiar o sofrimento da criança em minha opinião, mas a vantagens são criar laços de amizade (E1).

É preciso que haja e uma capacitação dos profissionais da área, para que a ludoterapia funcione de forma eficaz. Todos precisam estar inseridos nesse contexto, não apenas as crianças e seus pais assim como todos os profissionais de saúde envolvidos diretamente no cuidado de forma a tentar fazer com que esta situação não seja somente de dor.

Os autores Maia, Ribeiro \& Borba (2011) afirmam que é necessário que toda a equipe de enfermagem se sensibilize e compreenda o processo brincar para a criança como sua principal atividade. Para isto a equipe precisa ser capacitada e estudar o significado do ato de brincar para a criança e como ela se expressa pelo lúdico visando o respeito a esta necessidade nos serviços de saúde.

É necessário apoio a esses profissionais para colocarem em pratica a abordagem lúdica, pois sabe- se que muitas vezes os profissionais têm pouco tempo para desempenhar todas as atividades e imprevistos que acontecem durante a jornada de trabalho. O que demonstra nas falas sobre o que leva os profissionais a não usarem a abordagem lúdica no cuidado a criança hospitalizada:

Muitas vezes ofuncionário está sem paciência à rotina questão de hábitos ou não quer se envolver emocionalmente então faz só o necessário (T/A2).
Para mim é falta de conhecimento adequado [...], se tivesse uma capacitação ou apoio seria mais fácil por em prática a abordagem (E3).

Falta de conhecimento, medo e muitos procedimentos para realizar nos preocupam muito com a técnica (T/A4).

Tem pessoas que são mais fechadas, as vezes não fazem porque não gostam são poucos que fazem além (T/A1).

Acho que o envolvimento com a sistematização em que tem que fazer isso ou aquilo, horário [...] se tivéssemos alguém que estivesse junto quando fossemos realizar os procedimentos brincando ou com os brinquedos ali seria mais fácil porque fica tudo nas costas da enfermagem (E2).

O que pode levar a não usar é questão de tempo (E1).

As pessoas não gostam de apostar no novo porque precisa de dedicação e tempo e preferem ficar na rotina mesmo e se tornam mecanizadas (T/A1).

A maioria dos profissionais acredita que o tempo é uma das causas que levam os profissionais a não usarem a abordagem lúdica, muitos ainda relatam a falta de conhecimento cientifico, capacitação, apoio e muitos acham que o motivo é da rotina onde as pessoas se tornam mecanizadas e não se dão conta disso no dia- a- dia.

Os autores Sousa et al. (2011) reafirmam isso quando dizem que há um despreparo dos profissionais na forma de abordagem à criança-família no cotidiano da internação hospitalar, faltam-lhes noções de áreas do conhecimento que deem suporte para trabalhar com as necessidades do binômio, e para estabelecer processos efetivos de comunicação.

Tem-se a necessidade de um melhor preparo técnico científico dos profissionais de 
enfermagem para o atendimento à família da criança em tratamento, aliado a um maior esforço por parte das instituições em promoverem uma reestruturação das unidades, melhorando sua infraestrutura e capacitando os profissionais para um cuidado mais humano.

Ainda hoje, a aplicação da abordagem lúdica apresenta inúmeras dificuldades, seja de recursos humanos, materiais ou estruturais. Porém, não devem justificar a privação do direito da criança de brincar e receber um cuidado mais humano e afetivo. Assim, é necessária uma instrumentalização da equipe de enfermagem para que conheça seus benefícios e potencializar a prática do cuidar.

\section{Considerações finais}

Nesse estudo buscou-se conhecer a percepção da equipe de enfermagem em relação ao lúdico na abordagem à criança hospitalizada, demonstrando a relevância da criação de vínculos de confiança entre enfermagem, criança e família destacando-se o brincar e o diálogo como dispositivos que auxiliam nessa vinculação.

Percebe-se fragilidades no que concerne o preparo técnico-científico da equipe de enfermagem para utilizar a abordagem lúdica na prestação da assistência à criança hospitalizada, visto que, alguns dos participantes desconhecerem o conceito e as técnicas aplicadas à ludoterapia, esse tema teve escassa ou nenhuma abordagem na formação acadêmica ou profissional de todos os entrevistados. Alguns imaginam que falta tempo e que algum momento pode atrapalhar e adiar o procedimento.

Sendo assim, espera-se que este estudo contribua para o desenvolvimento de ações que promovam um cuidado mais humanizado da enfermagem e que atue de forma mais eficaz na redução dos transtornos provocados pela hospitalização na criança e, também, alertar as instituições da importância de implantação dessa modalidade para que ela faça parte da assistência integral à criança, visando sempre o seu bem-estar.

\section{REFERÊNCIAS}

- Acioli, S., Kebian, L. V. A., Faria, M. G. D. A., Ferracicioli, P., \& Correa, V. D. A. F. (2014). Práticas de cuidado: o papel do enfermeiro na atenção básica. Rev. enferm UERJ, 22(5), 637-42.

- Almeida, F. A., \& Sabatés, A. L. (2008). Enfermagem pediátrica: a criança, o adolescente e sua família no hospital. $1^{\circ}$ SP: ed. Barueri.

- Almeida, D. V. (2012). Alteridade: ponto de partida da humanização dos cuidados em saúde? Revista Baiana de Enfermagem, 26(1), 399-407. Recuperado de https://portalseer.ufba.br/index.php/enfermagem/article/ view/6332/5989

- Biscarde, D. G. D. S., Pereira-Santos, M., \& Silva, L. B. (2014). Formação em saúde, extensão universitária e Sistema Único de Saúde (SUS): conexões necessárias entre conhecimento e intervenção centradas na realidade e repercussões no processo formativo. Interface-Comunicação, Saúde, Educação, 18(48), 177-186.

- Brito, T. R. P. D., Resck, Z. M. R., Moreira, D. D. S., \& Marques, S. M. (2009). As práticas lúdicas no cotidiano do cuidar em enfermagem pediátrica. Rev Enferm Anna Nery, 13(4), 802-8.

- Castro, D. P., Andrade, C. U. B., Luiz, E., Mendes, M., Barbosa, D., \& Santos, L. H. G. (2010). Brincar como instrumento terapêutico. Pediatria (São Paulo), 32(4), 246-54.

- Côa, T. F., \& Pettengill, M. A. M. (2011). A experiência de vulnerabilidade da família da criança hospitalizada em Unidade de Cuidados Intensivos Pediátricos. Revista da Escola de Enfermagem da USP, 45(4), 825-832.

- Cruz, D. S. M., Rocha, S. M. L., \& Marques, D. K. A. (2013). O lúdico na hospitalização: percepção de mães 
de crianças hospitalizadas quanto ao projeto de extensão “Anjos da Enfermagem”. Rev. Ciênc. Saúde Nova Esperança, 2(11), 131-42.

- He, H. G., Zhu, L., Li, H. C. W., Wang, W., Vehviläinen-Julkunen, K., \& Chan, S. W. C. (2014). A randomized controlled trial of the effectiveness of a therapeutic play intervention on outcomes of children undergoing inpatient elective surgery: study protocol. Journal of advanced nursing, 70(2), 431-442.

- Falbo, B. C. P., Andrade, R. D., Furtado, M. C. D. C., \& Mello, D. F. D. (2012). Estímulo ao desenvolvimento infantil: produção do conhecimento em enfermagem. Revista Brasileira de Enfermagem, 65(1), 148-154.

- Frota, M. A., Gurgel, A. A., Pinheiro, M. C. D., Martins, M. C., \& Tavares, T. A. N. R. (2007). O lúdico como instrumento facilitador na humanização do cuidado de crianças hospitalizadas. Cogitare enferm, 12(1), 69-75.

- Jansen, M. F., Santos, R. M., \& Favero, L. (2010). Benefícios da utilização do brinquedo durante o cuidado de enfermagem prestado à criança hospitalizada. Revista Gaúcha de Enfermagem, 31(2), 247.

- Leite, T. M. C., \& Shimo, A. K. K. (2008). Uso do brinquedo no hospital: o que os enfermeiros brasileiros estão estudando. Rev Esc Enferm USP, 42(2), 389-95.

- Lemos, L. M. D., Pereira, W. J., Andrade, J. S., \& Andrade, A. D. S. A. (2010). Let us care with plays?. Revista brasileira de enfermagem, 63(6), 950-955.

- Maia, E. B. S., Ribeiro, C. A., \& Borba, R. I. H. (2008). Brinquedo terapêutico: benefícios vivenciados por enfermeiras na prática assistencial à criança e família. Revista Gaúcha de Enfermagem, 29(1), 39.

- Lima, K. Y. N., \& Santos, V. E. P. (2015). O lúdico como estratégia no cuidado à criança com câncer. Revista Gaúcha de Enfermagem, 36(2), 76-81.

- Magnabosco, G., Tonelli, A. L. N. F., \& Souza, S. N. D. H. (2008). Abordagens no cuidado de enfermagem à criança hospitalizada submetida a procedimentos: uma revisão de literatura. Cogitare enferm, 13(1), 103-108.

- Minayo, M. C. (2012). O desafio do conhecimento: pesquisa qualitativa em saúde. $12^{\mathrm{a}}$. ed. - $1^{\mathrm{a}}$ reimpressão, São Paulo: Hucitec, p. 407.

- Maia, E. B. S., Ribeiro, C. A., \& Borba, R. I. H. (2008).
Brinquedo terapêutico: benefícios vivenciados por enfermeiras na prática assistencial à criança e família. Revista Gaúcha de Enfermagem, 29(1), 39.

- Mohan, S., Nayak, R., Thomas, R. J., \& Ravindran, V. (2015). The Effect of Entonox, Play Therapy and a Combination on Pain Relief in Children: A Randomized Controlled Trial. Pain Management Nursing, 16(6), 938943.

- Nunes, C. J. R. R., Rabelo, H. D., Falcão, D. P., \& Picanço, M. R. A. (2013). A importância da brinquedoteca hospitalar e da Terapia Ocupacional sob a óptica da equipe de enfermagem de um hospital público do Distrito Federal/ The importance of hospital playroom and Occupational Therapy from the perspective of the nursing team of a. Cadernos de Terapia Ocupacional da UFSCar, 21(3).

- Paladino, C. M., Carvalho, R., \& Almeida, F. A. (2014). Brinquedo terapêutico no preparo para a cirurgia: comportamentos de pré-escolares no período transoperatório. Revista da Escola de Enfermagem da USP, 48(3), 423-429.

- Schneider, C. M., \& Medeiros, L. G. (2011). Criança hospitalizada e o impacto emocional gerado nos pais. Unoesc Ciênc ACET, 2(2), 140-54.

- Souza, L. P. S., Silva, C. C. D., Brito, J. C. A. D., Santos, A. P. D. O., Fonseca, A. D. G., Lopes, J. R., \& Souza, A. A. M. D. (2012). O Brinquedo Terapêutico e o lúdico na visão da equipe de enfermagem. J Health Sci Inst, 30(4), 354-8.

- Sikilero, R., Morselli, R. \& Duarte G. (1997). Recreação uma proposta terapêutica. In: Ceccim, R. B. Carvalho P. R. Organizadores. Criança hospitalizada atenção integral como escuta à vida. Porto Alegre: Editora da Universidade Federal do Rio Grande do Sul; p.59-65. 